\author{
Military Technical College \\ Kobry El-Kobbah, \\ Cairo, Egypt.
}

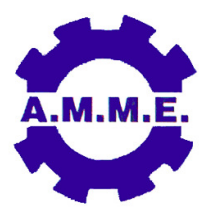

\title{
REVIEW ON SHEET METAL FORMING PROCESS OF ALUMINIUM ALLOYS
}

\author{
A. Ismail ${ }^{1}$ and M.S. Mohamed ${ }^{2,3}$
}

\begin{abstract}
The application of aluminum alloys in automotive and aerospace industries has been growing significantly in the last 20 years. Due to their high specific strength, aluminum became a strong replacement for steel particularly at automotive manufacturing. However, to deform a complex panel part from aluminum is quite challenging specifically at cold forming condition in which the formability is quite low. Many attempts have been processed to improve the formability problem of the aluminum alloy such warm forming, hot forming, superplastic forming and Hot forming and cold die quench (HFQ) processes. This paper presents a critical survey for different forming methods and identifying the advantages and drawbacks for each method. This review will help researcher to be familiar about the history, development and state of art of metal forming processes of aluminum sheet alloys.
\end{abstract}

\section{KEY WORDS}

Aluminum Alloys, Formability, Automotive industry, Warm forming, Superplastic, Hot stamping, HFQ.

1 Teaching Assistant, Dept. of Mechanical Engineering, Helwan University, Helwan, Egypt.

2 Research Fellow, Advanced Forming Research Centre (AFRC), Strathclyde University, Glashow, U.K. and Assistant professor at Dept. of Mechanical Engineering, Helwan University, Helwan, Egypt.

3 Corresponding Author: Dr. M. Mohamed, Email: Mohamed.mohamed@strath.ac.uk, Tel: +44141534 5510, Mob: +447712155969 Web: www.strath.ac.uk/afrc 


\section{INTRODUCTION}

The need of light metal in the automotive and aerospace industries has been increased recently in both structural and body parts. Using aluminum alloys have fulfilled this need as a replacement of steel. Strength and formability are the main material properties, which are very crucial for industrial applications. The formability of aluminum alloys are quit low particularly at cold forming condition. Series aluminum alloys $5 \mathrm{xxx}$ have the largest formability range and can be formed at room temperature. In addition, it has the lowest strength; While some aluminum alloys (6xxx and $7 x x x$ ) have higher strength than 5xxx but very difficult to form at room temperature. Forming at elevated temperature either warm or hot forming is developed in order to increase the formability, allowing forming of complex parts while maintaining the required mechanical properties. Forming at elevated temperature is not an easy task; the processes involves heating system , control of blank and die temperatures, challenges in cycle times transfer system and lubrication. The aim of the work is to introduce the different forming techniques of aluminum alloys sheets, providing a critical survey on the advantages and drawbacks of each technique.

\section{APPLICATIONS OF ALUMINUM AND ITS ALLOYS}

\section{Automotive Applications}

Aluminum will play a significant role in future car generations as its material properties have many advantages and open the way for new applications in the automotive industry (Sulaiman [1]; Kleiner et al. [2]). Indeed, developments in the aluminum industry, including improving the mechanical properties of aluminum alloys by adding various alloying elements has opened a wide field of applications for these alloys, particularly in the automotive and aerospace industries (Kleiner et al. [3]). The application of aluminum alloy in the automotive industry has increased more than $80 \%$ in the past 5 years. In 1996 a total of $110 \mathrm{~kg}$ of aluminum alloys were used in a vehicle. This amount is predicted to increase to 250 or $340 \mathrm{~kg}$ regardless of the structural applications (Miller et al. [4]).New developments in aluminum alloys have opened a wide range of applications of wrought aluminum in place of aluminum castings. Wrought aluminum alloys are produced from cast ingots, which are prepared for subsequent mechanical processing (Polmear [5]). The microstructures and mechanical properties of wrought aluminum alloys are significantly dependent on various working operations and thermal treatments. For automotive applications, the most used aluminum alloy series is the non-heat treatable Al-Mg (AA5xxx series) and the heat-treatable Al-Mg-Si (AA6xxx series) alloys. Due to the variations in chemical composition and processing, AA5xxx are optimized for strength and corrosion resistance in vehicle chassis and AA6xxx are optimized for high formability and age hardening response in auto body sheets panels. The current $6 \mathrm{xxx}$ alloys used for autobody sheets are AA6016 and AA6111 and, more recently, AA6181 and AA6082 were added for recycling aspects. AA6111 and AA6082 are usually used for the outer body panels which combine high strength with good formability as shown in Fig. 1 (Hodkinson and Fenton [6]).[7,8]. 


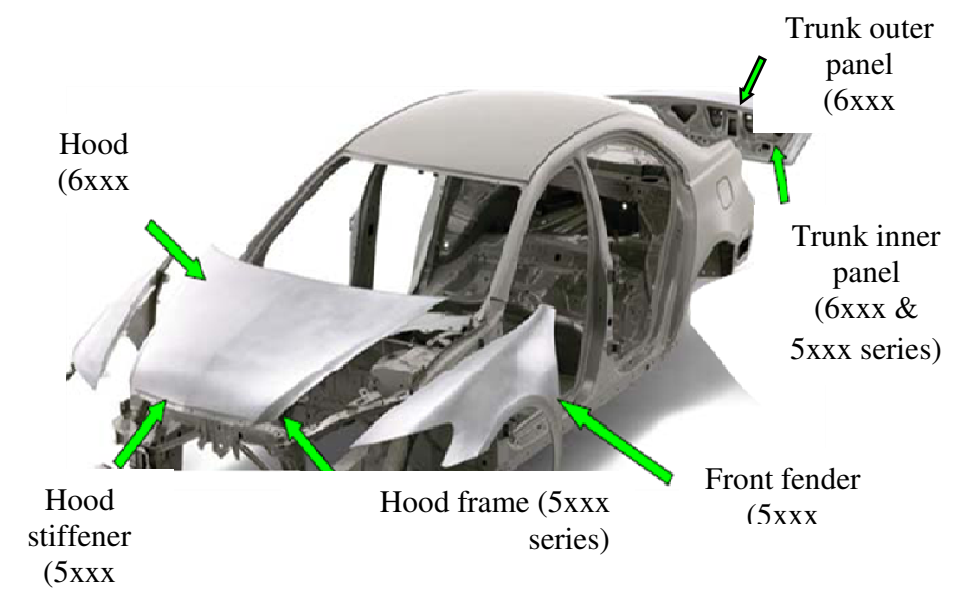

Fig.1. Applications of aluminum alloys in the automotive components of a typical passenger car [9].

\section{Aerospace Applications}

Aluminum-Lithium (Al-Li) alloys are usually used in such critical application due to its lightweight, excellent corrosion resistance, good strength and toughness combination and compatibility with standard manufacturing techniques. It used for many aircrafts parts such as leading and trailing edges, engine, wing skin, seat track and many other parts as shown in Figs. 2 a, b and c [8].

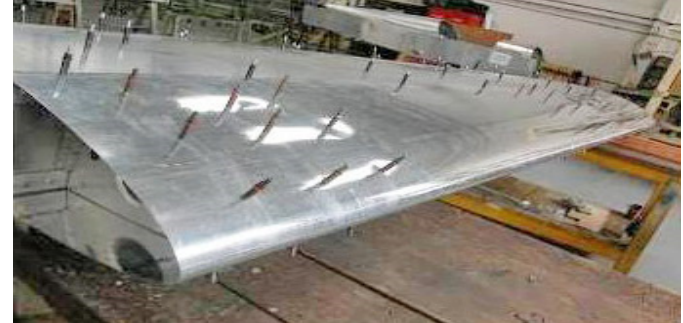

(a)

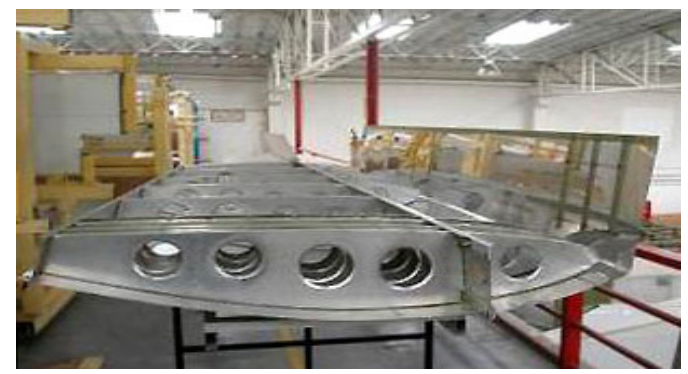

(b)

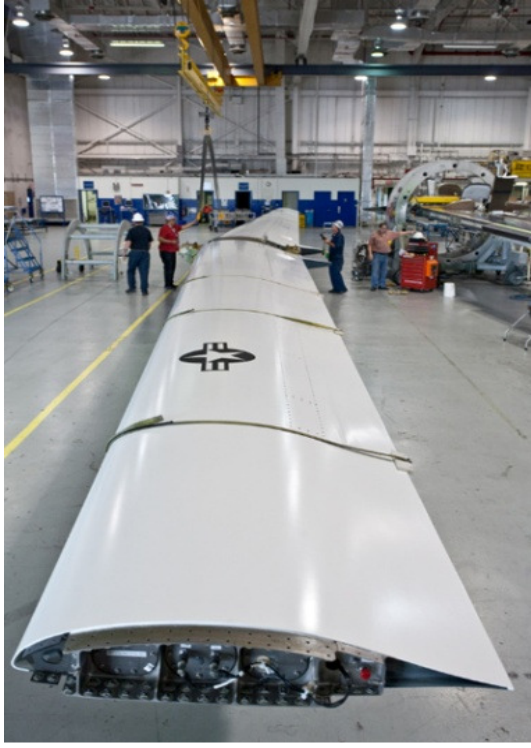

(C)

Fig.2. (a) Wing skin (b) Wing ribs made from aluminum alloys and (c) Final wing; upper skin and ribs are made of aluminum alloys $[10,11]$. 


\section{FORMING OF ALUMINIUM ALLOY PANEL COMPONENTS}

\section{Traditional Cold Forming}

Cold-rolled steel sheet is the traditional manufacturing process for automotive body panels. In the past few years, there are many attempts by automotive manufacturers to use AA5xxx and AA6xxx aluminum alloys in manufacturing automotive components in order to reduce the weight of their models Fig.3. For Age hardened aluminum alloy (AA6xxx) sheet components are normally formed either in the T4 condition (solution heat treated and quenched), followed by artificial ageing for higher strength, or in the T6 condition (solution heat treated, quenched and artificially aged).In this process, the material is heated to its Solution Heat Treatment (SHT) temperature and then held for a sufficient period of time, and all precipitates are taken into the matrix giving one single phase. The heat-treated material is rapidly cooled to room temperature to freeze this super-saturated state within the material. Once the material has been thermally treated and modified to the required mechanical properties, it is cold-deformed in the T6 condition into the required shape (M. Mohamed [13]).

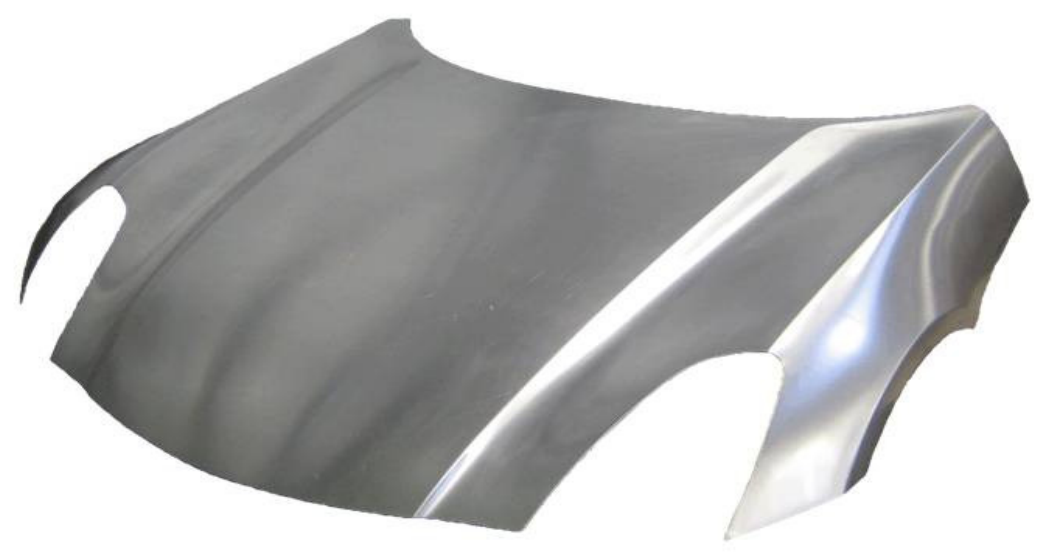

Fig.3. Cold forming aluminum body panels [12].

There are significant drawbacks of the traditional method for forming aluminum alloys panel parts. First is the poor formability Fig.4 of the material due to the hardening and strengthening processes carried out on the material, even in T4 forming. Secondly, after forming, if young's modulus is low, the component is more likely to be affected by spring back and wrinkling problems Fig.5. This means extra effort is needed to compensate for these problems. [14,15].

\section{Warm Forming}

The limited ductility for aluminum at cold forming condition is improved by conducted the process at Warm forming process. There are many challenges in such process 


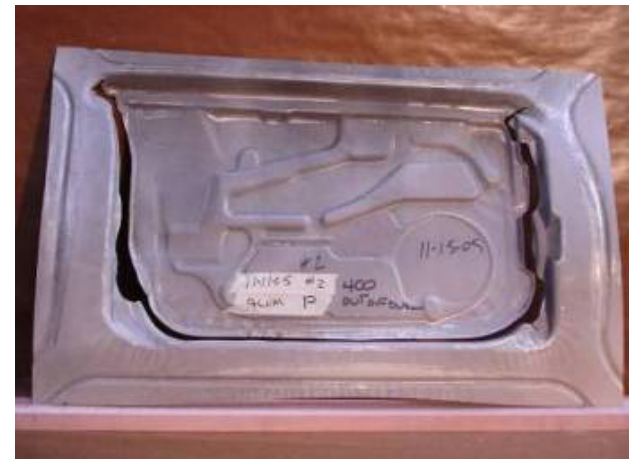

(a)

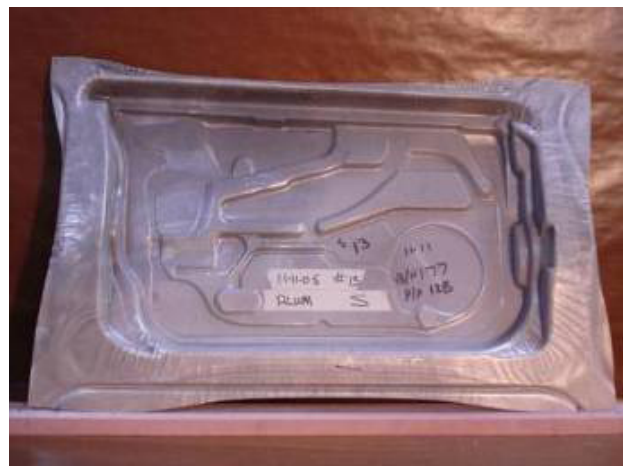

(b)

Fig.4. Inner door a) poor formability at room temperature lead to failure. b) Warm forming of the inner door. [15].

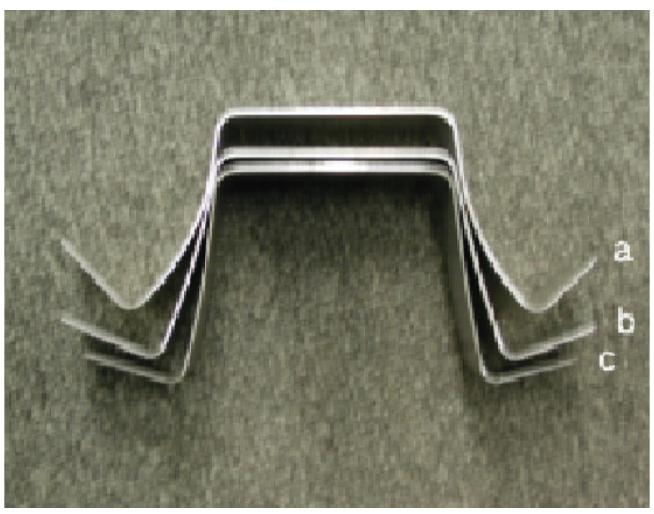

Fig.5. Effect of Springback on A5182 formed at a) room temperature b) $250^{\circ} \mathrm{C}$ and c) formed steel at room temperature .[14]

such as heating the components and controlling its temperature, lubrication, selection of the appropriate forming press, cycle time, and increased cost $[14,15,16]$.

In isothermal elevated temperature forming (heated dies); the die system requires complex heating strategies, with high tooling cost and relatively slow cycle time. It is also very difficult to achieve uniform temperature condition and maintain a steady die temperature. $[15,16,17]$.In this process Fig. 6 the aluminum alloy blank is heated between $\left(240-260^{\circ} \mathrm{C}\right)$ and then formed in a conventional hydraulic press at roomtemperature. $[15,16]$.

In a recent study conducted [17] for Automotive Research (USCAR), non-isothermal elevated temperature forming technology was used in a situation that required only heated sheet metal and room temperature dies. The purpose of the study was to optimize the technology in terms of production data and part cost. The study showed an Al 5182 door inner could be formed successfully at about 250 c .Fig.7 [17].

AMAG TopForm use the 7xxx aluminum alloy fully hardened T6 temper for warm forming of high-strength components with considerable energy absorption capacity. 


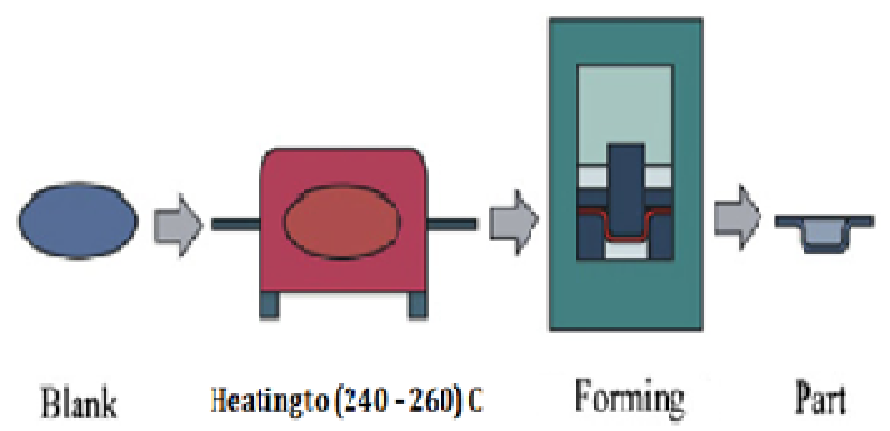

Fig.6. Illustration of warm stamping in cold dies process [17].

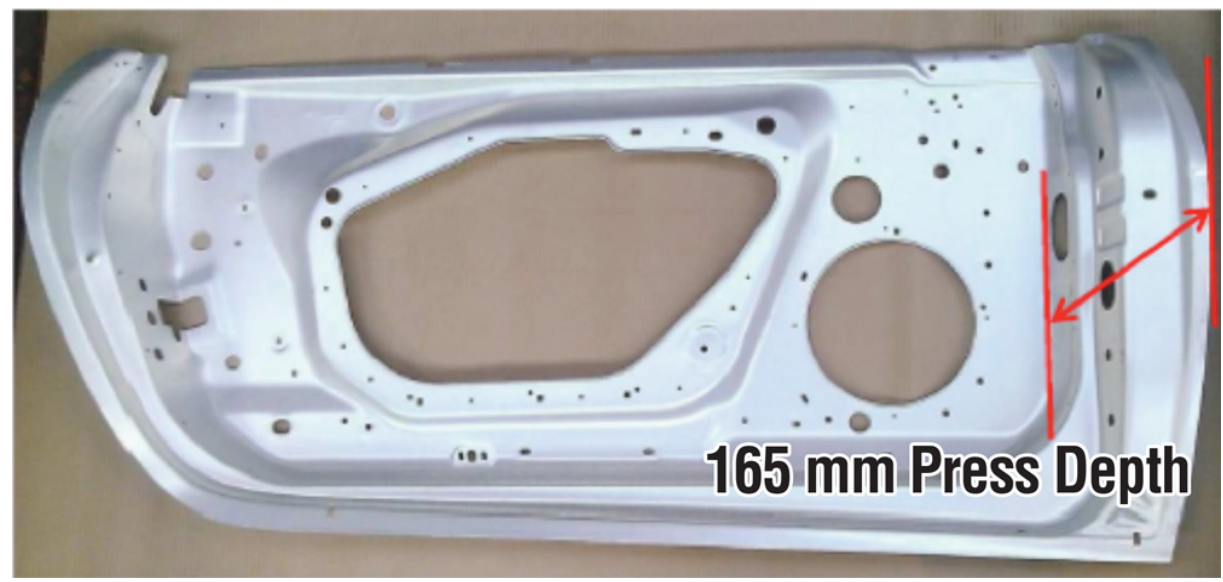

Fig.7 .Warm-formed door inner from Al 5182 [17].

The side impact beams in the BMW in Fig. 8 are formed from 7xxx aluminum alloy fully hardened $\mathrm{T} 6$ temper in the $200^{\circ} \mathrm{C}$ temperature range with forming speed equal to that used in traditional cold forming of aluminum alloy. [18].

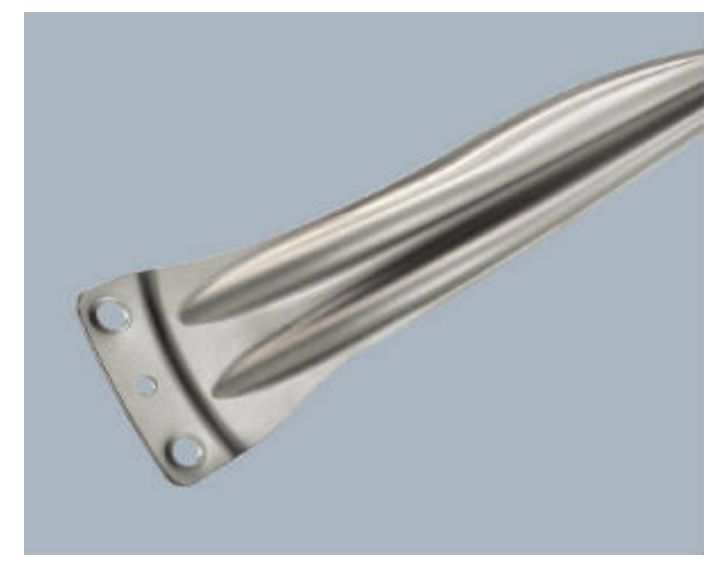

Fig.8. Side impact beams in the BMW i8 by AMAG TopForm [18]. 
Another warm forming process was investigated recently to develop the forming process for automotive panels of Al5182 and Al 5754.The process consist of three steps: Performing, Annealing, and Finish forming.[19].

\section{Preforming, Annealing, and Finish Forming}

It involves drawing the blank as deep as possible without necking followed by annealing the blank at about $350^{\circ} \mathrm{C}$ to remove the cold working stresses and then drawing the blank to the final shape as shown in Fig. 9 [19].

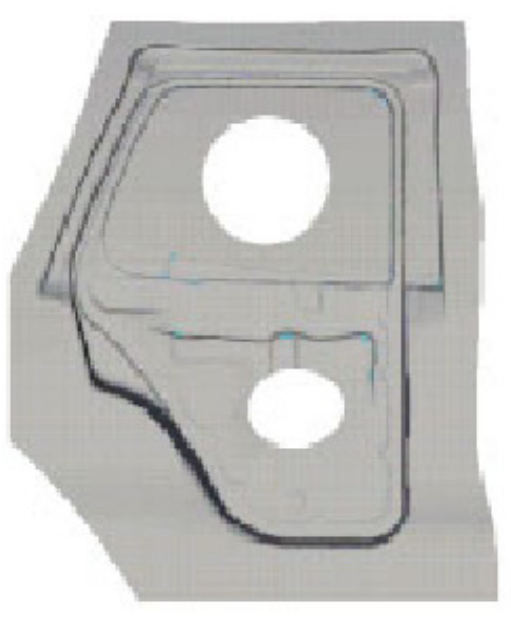

(a)

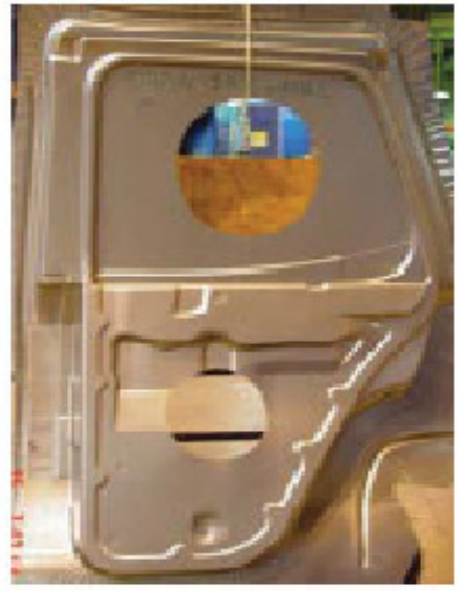

(b)

Fig.9. The preform-anneal process was used to produce this 1.15-mm-thick inner door panel made of Al 5182-O3. a) Simulate of final drawing b) inner door panel [19].

This process has a high cycle time especially in the transfer process. Hardness measurement shows that this process could not be able to fully anneal the panels, and the original hardness of the incoming material was not achieved. Also this is not a one-step process the cost associated with extra processing steps makes this process cost-prohibitive. [19]

\section{HOT FORMING}

\section{Hot Stamping}

At room temperature, the $5 x x x$ series aluminum alloys can be formed which have the largest formability range, but also the lowest yield and tensile strength. The 7xxx series alloys have the highest strength and then the 6xxx series. [16]

The 7xxx series with T6 temper cannot be formed at room temperature. The formability of this alloy can be improved with elevated-temperature forming. Either 
warm forming (less than $250 \mathrm{c}$ degrees) or hot forming (about $475^{\circ} \mathrm{C}$, the alloy's solvus temperature) can be used; see Fig.10 [16].

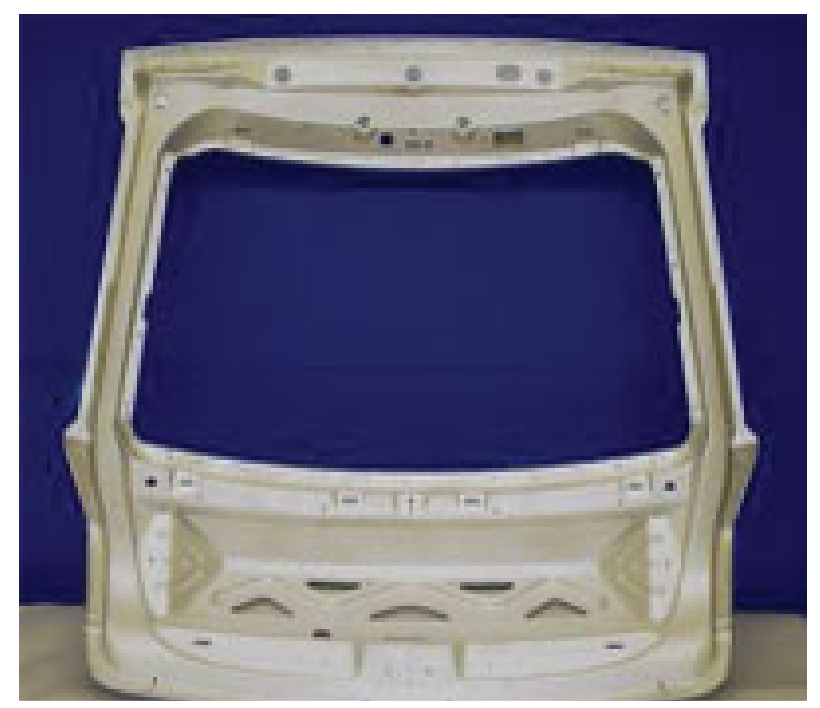

Fig.10. Hot forming of aluminum alloy Chevrolet Malibu Maxx lift gate [16].

Forming of aluminum alloy sheet at high temperature produce a product has a different microstructure and mechanical properties than the original sheet or it may remove any heat treatment has been done to the sheet .The solution for such problem is ( HFQ ) forming .[16,17].

\section{Isothermal Superplastic Forming (SPF)}

High-strength superplastic aluminum alloys such as 2004-alloy (Al-Cu system) and 7475-alloys (Al-Zn-Mg-Cu system) which have very fine grain structure of about 10 $\mu \mathrm{m}$ in diameter when deformed at high temperatures of $(400-500){ }^{\circ} \mathrm{C}$ and low strain rate $\left(10^{-4}-10^{-3}\right) / \mathrm{s}$, it shows extremely large degree of ductility. This process involves press a heated blank to a heated die surface using air or gas pressure at slow deformation speed as shown in Fig.11 [19].

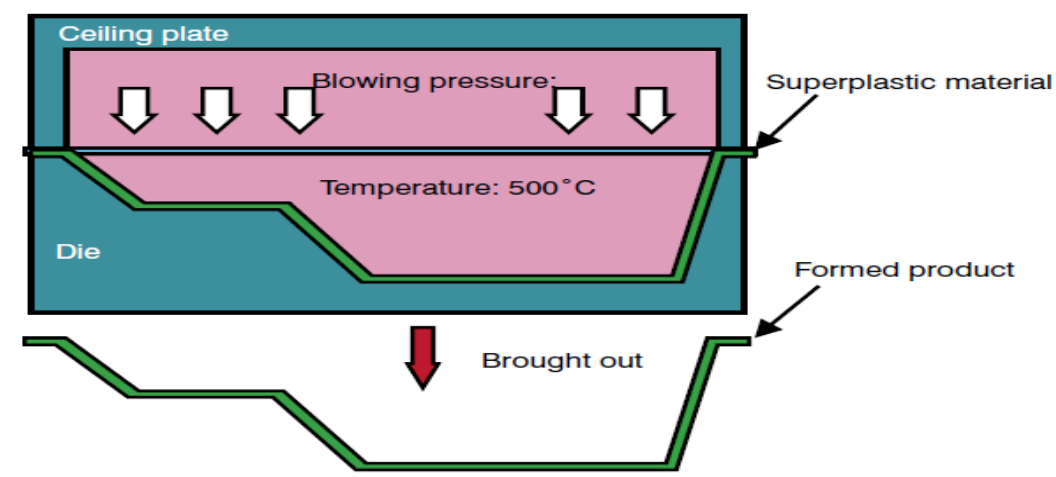

Fig.11. Illustration of typical superplastic forming process [20]. 
Recently, Super-plasticity has been used to form components for automotive applications. In the automotive industry, aluminum alloys are deformed at a faster rate (in contrast to aerospace applications) to provide high volume production. The significant increase in the formability of aluminum alloys by using superplastic forming allows for more complex to be manufactured, as shown in Fig.12 which can, in turn, eliminate using fasteners and joints [20,21].

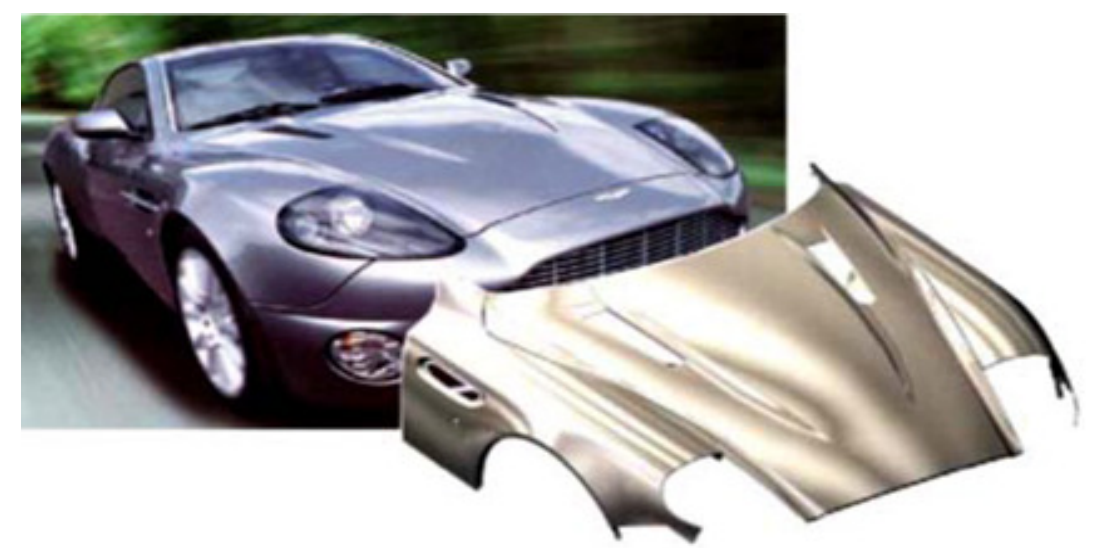

Fig.12. Superplastic formed aluminum sheets [21].

The Wing doors Fig.13. of the new Mercedes AMG SLS is made by SPF from a 5xxx alloy with a high $\mathrm{Mg}$ content, which was developed for superplastic forming processes by means of a special alloy composition and production route by (AMAG TopForm).[22].

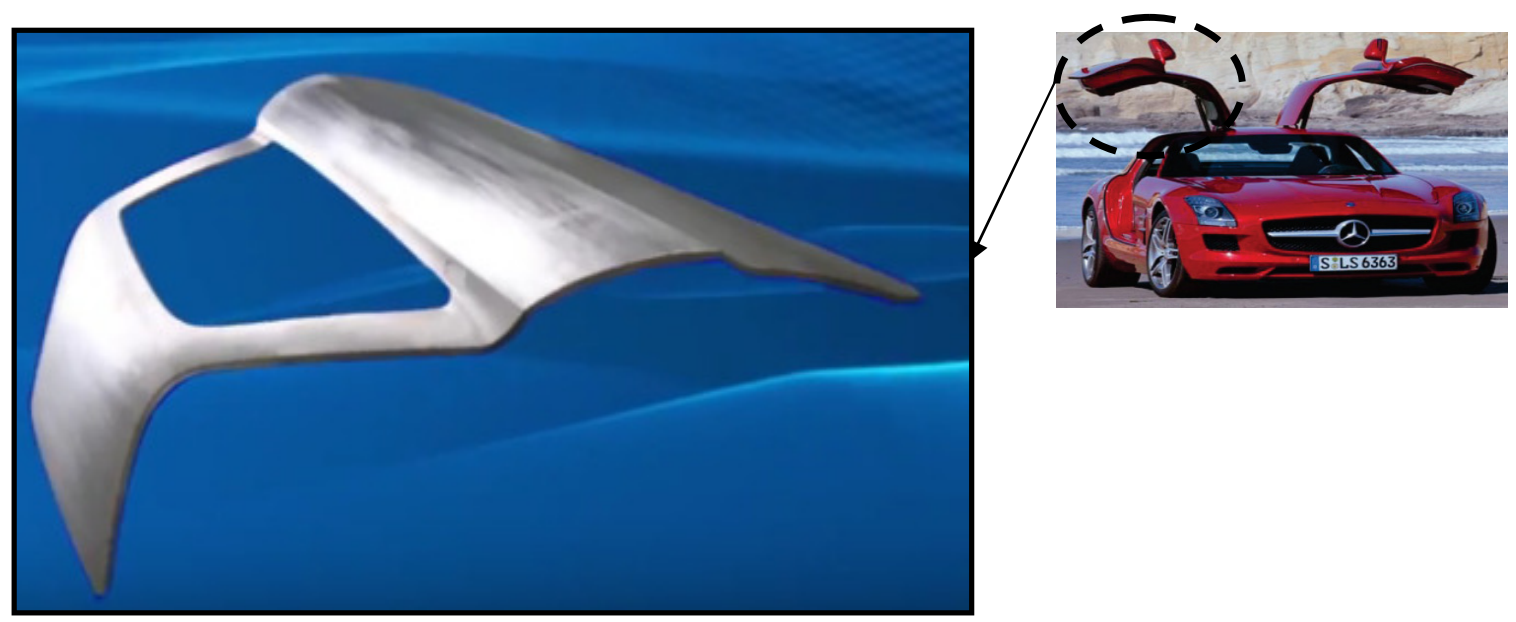

Fig.13. Wing doors out of superplastic forming AMAG TOPform, Mercedes Bens AMG SLS [22].

Superplastic forming takes place using high temperatures $\left(450-500^{\circ} \mathrm{C}\right)$ and low forming speeds, which allows the forming of more complex parts than the traditional forming methods. AMAG TopForm uses the same technique to form the fenders of the Bentley continental Gt Fig.14. [22] 


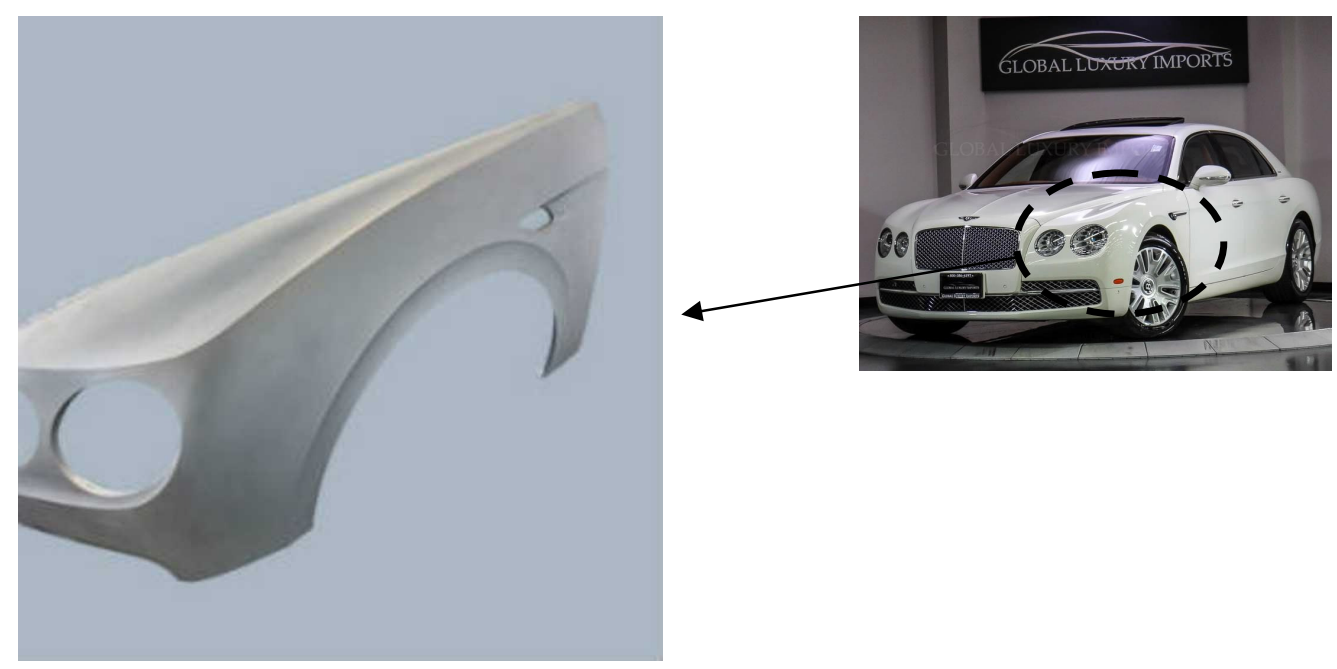

Fig.14. Fender out of superplastic forming for Bentley continental Gt by AMAG TOPform [22].

Superplastic forming provides more formability, more complex shapes and more homogenous thickness distribution; however, it is difficult to obtain uniform temperature in the tooling. Furthermore, the cycle time is relatively long. Thus, the process may be economical only in special applications and for low-volume production. [13]

\section{Heat Treatment Forming and In-Die Quench (HFQ)}

Hot Forming and cold die Quenching (HFQ) ® has been developed to overcome the formability, springback problems. In this process, the forming and quenching processes are combined together in one stage. This process can be used for forming complex-shaped components in one operation with high strength as well [(Garrett et al., 2005; Mohamed et al., 2008].[23,17]

The thermal profile of the newly developed HFQ process is shown in Fig.15 The aluminium blank is first heated to its SHT temperature (and subsequently held at the solution heat treatment (SHT) temperature for a specified period to dissolve all precipitates in the primary $\alpha$-Al matrix. $[17,18]$.The fully solution heat treated aluminium blank is then transferred to a press and formed between a set of cold dies, and subsequently held within the cold dies to quench the metal. There are two reasons for holding the formed part in the cold dies: one is that rapid quenching prevents the formation of coarse $\beta$-phase precipitates, particularly at grain boundaries; the second is to avoid thermal distortion of the formed part during quenching. The formed part is subsequently aged to enable the precipitates to be formed in a controlled way [23, 24].

An investigation in HFQ of AA6111 aluminium alloy cold-rolled sheet of initial thickness $2 \mathrm{~mm}$ is carried by [Jing ZHOU, 2014] for a Side-door impact beam. Fig.16 shows that the forming AA6111 aluminium alloy at room temperature leads to cracks,

® $\mathrm{HFQ}$ is a registered trademark owned by Impression Technologies Ltd. 


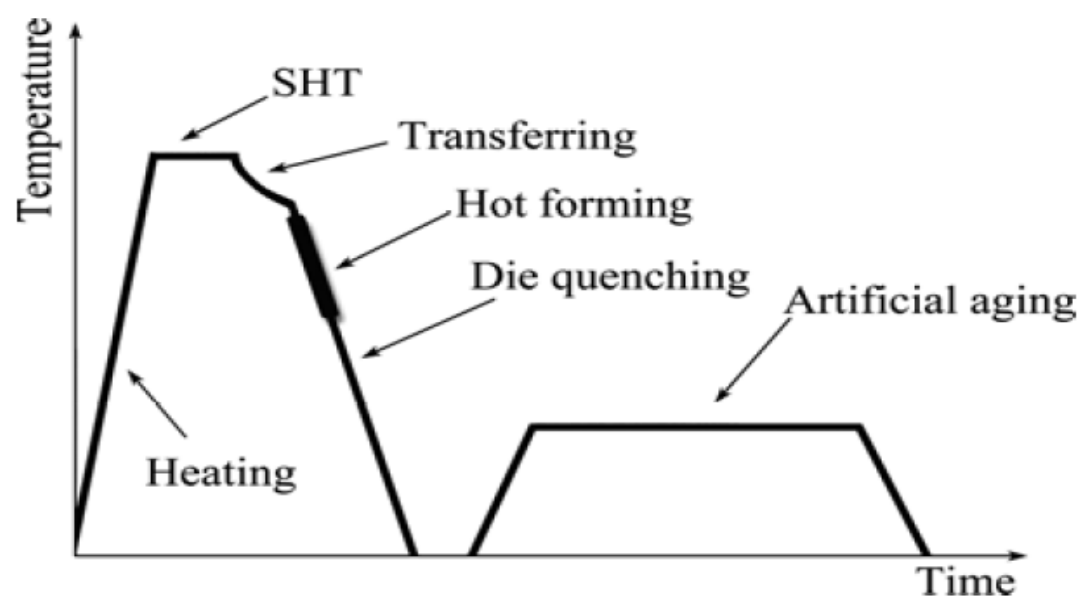

Fig.15. Schematic diagram showing temperature history of HFQ [24].
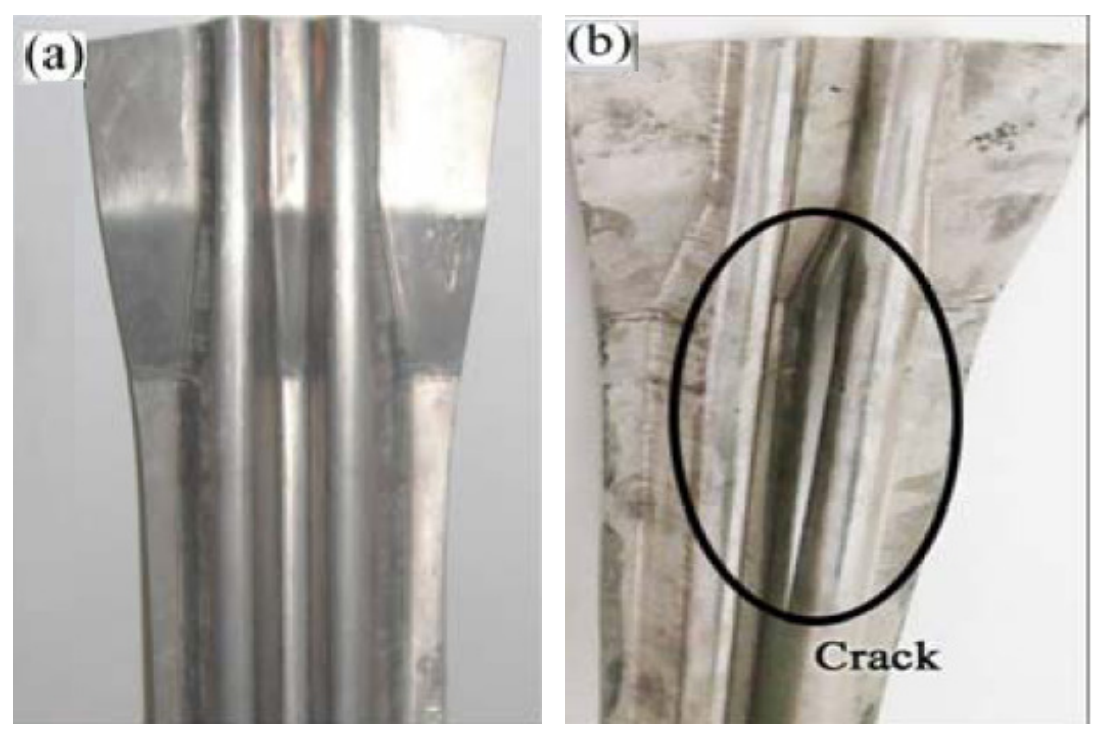

Fig.16. Side-door impact beam formed under a) HFQ, b) cold forming [24].

while forming by HFQ increase the formability of the blank, which lead to accepted product [24].

Fig.17 shows a car door inner for Lotus at R\&D center in Ulricehamn has been formed using HFQ. This high-strength aluminum alloy has been formed during a single forming procedure. The process fulfils the requirements for strength even though the material was stretched out up to $50 \%$ from a thickness of only 2 millimeters.[25,26]. 

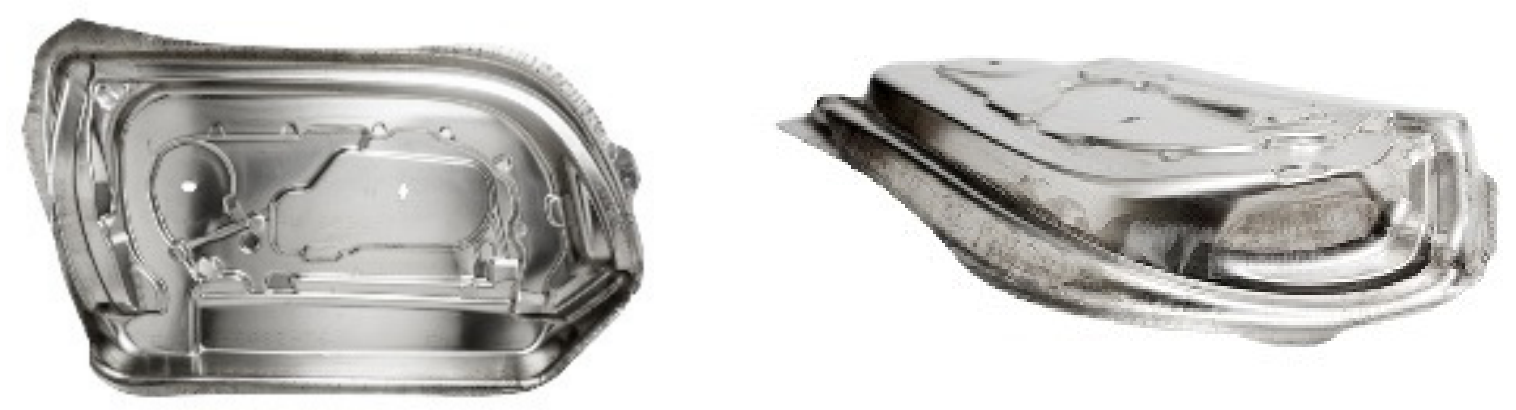

Fig.17. lotus inner door formed by HFQ [26].

\section{CONCLUSION}

In this paper, different techniques for forming of aluminium alloys sheets are reviewed. Forming at elevated temperature provide high formability especially for high strengthened alloys. Superplastic forming and HFQ are the most convenient processes for aluminium alloys; however, superplastic forming has high cycle time than HFQ. The most significant influence of HFQ process on the aluminum alloy blank is the improved formability allowing the manufacture of extremely complex, and single piece deep drawn panels, which would be difficult using conventional stamping methods.

\section{REFERENCES}

[1] Sulaiman, A. S., (2005), Finite Element Modelling and Characterisation of Springback and Drawability in Aluminum-Based Alloy. Department of Metallurgy and Materials, Birmingham, University of Birmingham. Degree Doctor of Philosophy, 1-184.

[2] Kleiner, M., Chatti, S., Klaus, A. (2006), Metal forming techniques for lightweight construction. International Journal of Materials Processing Technology, Proceedings of the 11th International Conference on Metal Forming 2006, 177(1-3), 2-7.

[3] Kleiner, M., Geiger, M., Klaus, A., (2003), Manufacturing of Lightweight Components by Metal Forming. CIRP Annals - Manufacturing Technology, 52(2), 521-542.

[4] Miller, W. S., Zhuang, L., Bottema, J., Wittebrood, A. J., De Smet, P., Haszler, A., Vieregge, A., (2000), Recent development in aluminum alloys for the automotive industry. Journal of Materials Science and Engineering, 280(1), 37-49.

[5] Polmear, I.J., (1995), Light Alloys - Metallurgy of the Light Metals. Third ed, Butterworth-Heinemann, Oxford.

[6] Hodkinson, R., and Fenton, J., (2000), Lightweight construction materials and techniques Lightweight Electric/Hybrid Vehicle Design. Oxford, Butterworth-Heinemann, 173-198.

[7] Ju"rgen Hirsch, Aluminium in Innovative Light-Weight Car Design,J.Materials Transactions, Vol. 52, No. 5 (2011) pp. 818 to 824. 
[8] Joseph R. Davis, ASM Specialty Handbook: Aluminum and Aluminum Alloys, ASM International, 1993.

[9] www.autoaluminum.org.

[10] http://www.zenithair.com/zodiac/xl/xl-qbk-photos1.html.

[11] http://www.triumphgroup.com/companies/triumph-aerostructures-voughtred-oak/capabilities/wings.

[12] http://articles.sae.org/5821/.

[13] MS Mohamed, J Lin, L Wang, D Balint, "Hybrid forming processes for production of lightweight high strength automotive panel parts", $\mathrm{J}$. International Heat Treatment and Surface Engineering,Vol.4,No.4,pp.160165(2010).

[14] Ken TAKATA, Warm Forming of Aluminum Alloys,J. NIPPON STEEL TECHNICAL REPORT No. 103 MAY 2013.

[15] Harrison, N., llinich, A., Friedman, P., Singh, J. et al., "Optimization of High-Volume Warm Forming for Lightweight Sheet," SAE Technical Paper 2013-01-1170, 2013.

[16] Ju, L., and Altan, T., "Forming Al Alloys at Elevated Temperatures, Part I" Stamping Journal, May/June 2015, p. 16.

[17] Ju, L., and Altan, T., "Forming Al Alloys at Elevated Temperatures, Part II Case Studies"- Stamping Journal, July/August, 2015, p. 16.

[18] https://www.amag.at/en/our-aluminium/automotive/structure.html.

[19] Billur, E., and Altan, T., "Warm Forming of Al Alloys in Automotive Industry", Stamping Journal, July/August, 2013, p. 20.

[20] Lang Lihui, Liu Kangning, Gaoshen Cai, Xiying Yang, A critical review on special forming processes and associated research for lightweight components based on sheet and tube materialsJournal: Manufacturing Review, 2014, Volume 1, Page 9.

[21] Jeswiet, J., Geiger, M., Engel, U., Kleiner, M., Schikorra, M., Duflou, J., Neugebauer, R., Bariani, P., Bruschi, S., (2008), Metal forming progress since 2000. CIRP Journal of Manufacturing Science and Technology, 1(1), 2-17.

[22] https://www.amag.at/en/our-aluminium/automotive/bodyshell.html.

[23] M. S. Mohamed, A.D. Foster, and J. Lin, "Solution heat treatment in HFQ process", J. Steel Research International. Cracow, Poland, 2008, 79(11): $160-167$.

[24] Jing ZHOU, Bao-yu WANG, Jian-guo LIN, Lei FU, Wen-yu MA, Forming defects in aluminum alloy hot stamping of side-door impact beam, Transactions of Nonferrous Metals Society of China, Volume 24, Issue 11, November 2014, Pages 3611-3620.

[25] http://www.pabgroup.co.uk/hfq-production-in-uk/

[26] http://us.aptgroup.com/news_events/news/News_LoCoLite 